\title{
Methodology Development and Validation of Amphotericin B Stability by HPLC-DAD
}

\author{
Marciela B. Montenegro, ${ }^{a}$ Stefânia P. de Souza, ${ }^{a}$ Raquel A. C. Leão, ${ }^{a, b}$ \\ Helvécio V. A. Rocha, ${ }^{c}$ Claudia M. de Rezende ${ }^{d}$ and Rodrigo O. M. A. de Souza ${ }^{\circledR *, a}$ \\ ${ }^{a}$ Grupo de Biocatálise e Síntese Orgânica, Instituto de Química, \\ Universidade Federal do Rio de Janeiro, 21941-909 Rio de Janeiro-RJ, Brazil \\ ${ }^{b}$ Escola de Farmácia, Universidade Federal do Rio de Janeiro, 21941-909 Rio de Janeiro-RJ, Brazil \\ 'Laboratório de Sistemas Farmacêuticos Avançados, Farmanguinhos/Fiocruz, \\ 22775-903 Rio de Janeiro-RJ, Brazil \\ ${ }^{d}$ Laboratório de Análise de Aromas, Instituto de Química, Universidade Federal do Rio de Janeiro, \\ 21941-895 Rio de Janeiro-RJ, Brazil
}

\begin{abstract}
The high worldwide consumption of antibiotics and their complex impurity profiles has drawn the attention of the scientific community to the development and validation of stability methods for these drugs. Amphotericin B is an antibiotic that is a natural fermentation product of bacterium Streptomyces nodosus, used as a broad-spectrum antifungal agent, and is highly unstable. For this reason, the objective of this work is the development and validation of an indicative method of stability by high performance liquid chromatography (HPLC) associated to diode array detector (DAD) for amphotericin B (AMB). To achieve this, the chromatographic profiles of acid, basic, oxidative and thermal degradation caused by $\mathrm{AMB}$ exposure to water and light were verified by HPLC-DAD, using an isocratic method under the following conditions: C18 chromatographic column $(200 \times 4.6 \mathrm{~mm}-5 \mu \mathrm{m})$, mobile phase composed of $65: 35$ of organic phase (methanol/ acetonitrile in $41: 18)$ /aqueous phase $\left(2.5 \mathrm{mmol} \mathrm{L}^{-1}\right.$ of disodium edetate, $\left.\mathrm{pH} 5.0\right)$, flow rate of $1.0 \mathrm{~mL} \mathrm{~min}^{-1}$, injection volume of $20 \mu \mathrm{L}$, column temperature $30 \pm 2{ }^{\circ} \mathrm{C}$ and wavelength of $383 \mathrm{~nm}$. After identification of these profiles, the method was validated according to recommendations of the International Conference on Harmonization guidelines, and then, the active pharmaceutical ingredient (API) peak purity grade, percentage of drug degradation, occurrence of impurities peak and its identification by mass spectrometry (MS) with electrospray ionization (ESI), under positive ionization mode, were evaluated. It is suggested that the main degradation products were amphotericin B (2), degradation product 1 (DP1) and degradation product 2 (DP2) in acid and oxidative medium. Amphotericin B was stable in the presence of water and at $70 \pm 2{ }^{\circ} \mathrm{C}$ for seven days.
\end{abstract}

Keywords: amphotericin B, forced degradation, degradation products, indicative stability method, HPLC-DAD

\section{Introduction}

Drug stability is related to external factors such as temperature, humidity and light, and to internal factors, like the physical and chemical properties of active substances and pharmaceutical excipients in a formulation. ${ }^{1}$ In face of this large variety of factors, increasingly stringent regulations have been imposed on pharmaceutical companies by regulatory agencies in various countries., ${ }^{2,3}$ One of these requirements is the elaboration of forced

*e-mail: rodrigosouza@iq.ufrj.br degradation studies, from the active pharmaceutical ingredient (API) to the final pharmaceutical product, in order to help the identification of possible degradation products and to establish the degradation routes and intrinsic stability of molecules. ${ }^{4}$

According to relevant legislation, the design for the forced degradation study should be based on the chemical and physical properties of the drug and the excipients used in the formulation, as well as on the storage conditions. The recommended stress conditions are: variation of temperature, humidity, susceptibility to acid and basic hydrolysis, oxidation, photolysis and presence of metal ions. ${ }^{1}$ The 
stress study aims to promote a small extent degradation, in order to avoid secondary degradations, and not to promote the total degradation of the compound. ${ }^{5}$ Forced degradation is the starting point for the development of an indicative stability method that is capable of accurately quantifying active ingredients without the interference of degradation products, process impurities, excipients or other potential impurities. ${ }^{5}$ The development of this method is also one of the requirements encompassed by the International Conferences on Harmonization (ICH) guideline, concerning impurities in new substances. ${ }^{6}$ Normally, the analytical technique used is high performance liquid chromatography (HPLC) associated to diode array detector (DAD).

Antibiotics are among the most studied drugs in these cases, since they are consumed worldwide and have complex impurity profiles, as they can be produced by fermentation, by fermentation followed by one or more synthetic steps (semisynthetic substances) or by chemical synthesis. ${ }^{7}$ Amphotericin B (AMB) (Figure 1) is an antibiotic that is a natural fermentation product of bacterium Streptomyces nodosus, ${ }^{8}$ used as a broad-spectrum antifungal agent ${ }^{9}$ and active against leishmaniasis. ${ }^{10,11}$ Aside from the more complex impurities profile, ${ }^{7}$ this drug is also unstable to $\mathrm{pH}$ changes, ${ }^{9,12}$ the presence of oxygen ${ }^{9,12}$ and hot and humid environments, ${ }^{13}$ being among the 110 substances contemplated in the list of drugs subject to degradation under tropical conditions $\left(50{ }^{\circ} \mathrm{C}\right.$ and $100 \%$ air humidity) of the World Health Organization (WHO). ${ }^{13}$

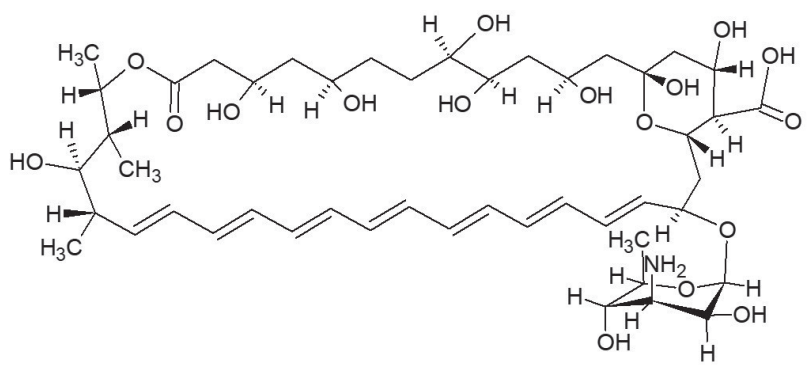

Figure 1. Amphotericin B.

In view of the above, the objective of this work is the development and validation of a methodology indicative of stability for AMB by HPLC-DAD from its exposure to stress conditions.

\section{Experimental}

\section{Reagents}

The reagents used were: amphotericin B-USP reference standard, batch No. K1M387, amphotericin B sample-batch: 20150624, ethylenediaminetetraacetic acid, disodium salt (EDTA-2Na) and HPLC grade methanol from Merck $^{\circledast}$ (Rio de Janeiro, Brazil), HPLC grade acetonitrile and dimethylsulfoxide (DMSO) from Tedia ${ }^{\circledR}$ (Rio de Janeiro, Brazil); 37\% hydrochloric acid and 20-60\% hydrogen peroxide from $\operatorname{Vetec}^{\circledR}$ (Rio de Janeiro, Brazil); granulated sodium hydroxide $\geq 98 \%$ from Sigma-Aldrich ${ }^{\circledast}$ (Rio de Janeiro, Brazil), and ultra-purified water obtained using a Milli-Q Plus system (Merck-Millipore ${ }^{\circledR}$, Rio de Janeiro, Brazil).

\section{Instrumentation and chromatographic conditions}

The method was developed using a Waters HPLC system model 2695D and a DAD detector model 2996. A Thermo BDS Hypersil C18 $(200 \mathrm{~mm} \times 4.6 \mathrm{~mm}-5 \mu \mathrm{m})$, column was used and mobile phase consisting of a 65:35 organic phase $(\mathrm{OP})$ (methanol:acetonitrile $(41: 18 \mathrm{v} / \mathrm{v}))$ and an aqueous phase (AP) (disodium edetate $2.5 \mathrm{mmol} \mathrm{L}^{-1}$ $\mathrm{pH}$ 5.0), with the following parameters: mobile phase flow rate $1.0 \mathrm{~mL} \mathrm{~min}^{-1}$, wavelength $383 \mathrm{~nm}$, run time $30 \mathrm{~min}$, injection volume $20 \mu \mathrm{L}$ and column temperature $30{ }^{\circ} \mathrm{C}$. The analyzes were processed using Empower ${ }^{\circledR} 3$ software.

In order to identify the degradation products, electrospray ionization mass spectrometry (ESI-MS) and electrospray ionization tandem mass spectrometry (ESI-MS/MS) were extracted on positive ionization mode using the Thermo Fisher Scientific quadrupole mass spectrometer LCQ FLEET. The operating conditions were: capillary voltage of $3.5 \mathrm{kV}$; source temperature at $320^{\circ} \mathrm{C}$ and cone voltage of $20-40 \mathrm{~V}$. Samples were injected using an automatic injection pump, WPS3000RS model. Full scan spectra were acquired in the range of $m / z 200$ to 1000 . The ESI-MS/MS spectra were acquired with energy of $28 \mathrm{eV}$ from the more expressive peaks of the full spectrum. In these cases, the additive used to promote the ionization of molecules was $0.01 \%$ formic acid. The spectra were treated with Xcalibur 2.0 SR2 software. All experiments were conducted in triplicate $(\mathrm{n}=3)$. The solutions $\mathrm{pH}$ values were measured using Mettler Toledo MP220 pH meter.

Amphotericin B stock solution and standard calibration analytical curve

The $1.0 \mathrm{mg} \mathrm{mL}^{-1} \mathrm{AMB}$ stock solution was prepared in DMSO and methanol (80:20, v/v). Different volumes of this solution were pipetted, diluted and filtered on $0.45 \mu \mathrm{m}$ polytetrafluoroethylene (PTFE) filter $\left(\mathrm{Millex}^{\circledR}\right)$ prior to injection. Eight AMB standard solutions $(0.05,0.06,0.07$, $0.08,0.09,0.1,0.11$ and $0.12 \mathrm{mg} \mathrm{mL}^{-1}$ ) were obtained for determining the standard calibration curve. 
Amphotericin B $0.1 \mathrm{mg} \mathrm{mL}^{-1}$ solution

$1.0 \mathrm{~mL}$ of the AMB stock solution was pipetted and transferred to a $10 \mathrm{~mL}$ volumetric flask and the volume was filled with methanol HPLC grade, homogenized and filtered on $0.45 \mu \mathrm{m}$ filter. The tests were performed in triplicate. The final concentration of this solution was of $0.1 \mathrm{mg} \mathrm{mL}^{-1}$.

\section{Method validation}

The method was validated following the ICH guideline. ${ }^{14}$ Considering that it is an API assay test, the parameters evaluated were linearity, specificity, accuracy, precision (repeatability), intermediate precision, limits of detection (LOD) and quantification (LOQ).

Linearity was calculated by linear regression of the areas of the API peak versus its concentration in eight standard solutions of AMB (0.05, 0.06, 0.07, 0.08, 0.09, $0.1,0.11$ and $0.12 \mathrm{mg} \mathrm{mL}^{-1}$ ) using the least squares method. The one-way variance analysis (ANOVA) evaluated the quality of the linear model fit performed by the software Origin ${ }^{\circledR} 2017 .{ }^{15}$ The specificity was evaluated by comparing the chromatogram of the degraded samples with the chromatogram of the $0.1 \mathrm{mg} \mathrm{mL}-1$ AMB solution $\left(\mathrm{t}_{0}\right)$. Accuracy was assessed by the percentage recovery value. The standard drug solution was added to AMB solution $\left(0.1 \mathrm{mg} \mathrm{mL}^{-1}\right)$, in the range of 50, 80, 100 and $120 \%$ of the sample concentration. Analyses were performed in triplicate. The mean recovery percentage should be within the range of $100 \pm 2 \%$ of the added amount. The relative standard deviation (RSD) between the replicates at each level should be at most $2.0 \%$. Precision (repeatability) was determined from the analysis of six samples at $100 \%$ of the AMB working concentration $\left(0.1 \mathrm{mg} \mathrm{mL}^{-1}\right)$. The RSD acceptance criteria was $2.0 \%$ or less. The intermediate accuracy was verified under the same conditions as repeatability. However, it was conducted by different analysts (two different analysts) on different days (two different days). Limit of detection (LOD) and limit for quantitation (LOQ) for AMB were determined based on signal-to-noise concept, using signal-to-noise ratio at 3:1 and $10: 1$, respectively.

\section{Suitability test of the chromatographic system}

The AMB concentrations and its degradation products obtained in the experiments were determined by using the calibration analytical curve for this API, in which data were reprocessed using Empower ${ }^{\circledR} 3$ software and the statistical analyses processed by Origin ${ }^{\circledR} 2017$ software. ${ }^{15}$ In order to check the adequacy system, five HPLC-DAD injections were performed of the $0.1 \mathrm{mg} \mathrm{mL}^{-1}$ of the AMB standard solution. The readings of the standard solutions (0.1 $\left.\mathrm{mg} \mathrm{mL}^{-1} \mathrm{AMB}\right)$ were defined by the parameters presented in Table 1.

Table 1. System suitability parameters ${ }^{16}$

\begin{tabular}{|c|c|}
\hline Parameter & Specification \\
\hline Relative standard deviation (RSD) & $\leq 2.0$ \\
\hline $\begin{array}{l}\text { Separation efficiency (number of } \\
\text { theoretical plates) }\end{array}$ & $\geq 2000$ \\
\hline Tail factor (peak symmetry) & $\leq 2.0$ \\
\hline Peak purity ${ }^{17}$ & $\begin{array}{c}\text { limit angle (LA) > peak purity } \\
\text { angle (PA) }\end{array}$ \\
\hline Capacity factor K' & $\geq 2.0$ \\
\hline
\end{tabular}

AMB forced degradation study

\section{Preparation of degraded samples}

In the AMB forced degradation study, the AMB sample solution $\left(0.1 \mathrm{mg} \mathrm{mL}^{-1}\right)$ was subjected to the stress conditions listed in Table 2.

Table 2. Parameters for the study of amphotericin B forced degradation

\begin{tabular}{lcc}
\hline Stress condition & Level & Exposure time \\
\hline Acid hydrolysis & $\mathrm{HCl} 0.01 \mathrm{~mol} \mathrm{~L}^{-1}$ & 0 \\
Alkaline hydrolysis & $\mathrm{NaOH} 0.001 \mathrm{~mol} \mathrm{~L}^{-1}$ & 0 \\
Oxidation & $3 \% \mathrm{H}_{2} \mathrm{O}_{2}$ & $\mathrm{t}_{1}=0 / \mathrm{t}_{2}=30 / \mathrm{t}_{3}=60 \mathrm{~min}$ \\
& $\left(\mathrm{t}_{2}\right.$ and $\left.\mathrm{t}_{3} 60 \pm 2{ }^{\circ} \mathrm{C}\right)$ & \\
Hydrolysis & water & $\mathrm{t}_{1}=60 / \mathrm{t}_{2}=240 \mathrm{~min}$ \\
Temperature & $\left(\mathrm{t}_{1}\right.$ and $\left.\mathrm{t}_{2} 60 \pm 2{ }^{\circ} \mathrm{C}\right)$ & $\mathrm{t}_{1}=24 / \mathrm{t}_{2}=168 \mathrm{~h}$ \\
Photolysis & $70 \pm 2{ }^{\circ} \mathrm{C}$ & $(7$ days $)$ \\
\end{tabular}

Where $t$ corresponds to the time of exposure of the AMB to the degrading agent.

The forced degradation study was performed with an initial concentration of $0.1 \mathrm{mg} \mathrm{mL}^{-1}$ of AMB. For this, $1.0 \mathrm{~mL}$ of the AMB stock solution was transferred to $10 \mathrm{~mL}$ volumetric flasks (amber) containing $1.0 \mathrm{~mL}$ of the stress solutions (Table 2) and then filled with methanol HPLC grade to obtain the final solution (working concentration

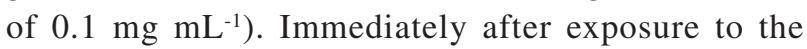
stressing agents $\left(0.01 \mathrm{~mol} \mathrm{~L}^{-1} \mathrm{HCl}, 0.001 \mathrm{~mol} \mathrm{~L}^{-1} \mathrm{NaOH}\right.$, $3.0 \%(\mathrm{v} / \mathrm{v}) \mathrm{H}_{2} \mathrm{O}_{2}$ and water), the AMB solutions were filtered directly into amber glass vials $(1.5 \mathrm{~mL})$ using a $0.45 \mu \mathrm{m}$ PTFE type hydrophilic membrane, the vials were capped and, when applicable, the solutions were exposed to $60 \pm 2{ }^{\circ} \mathrm{C}$, as shown in Table 2 . After degradation, the solutions were injected for chromatographic analysis. All 
readings were performed at a fixed wavelength of $383 \mathrm{~nm}$ and scanning wavelengths from 200 to $400 \mathrm{~nm}$. The assays were performed in triplicate.

For the temperature stressing conditions and the photodegradation study, $100 \mathrm{mg}$ of the raw material (powder) were submitted to a temperature of $70 \pm 2{ }^{\circ} \mathrm{C}$ in a Binder VD115 oven for $24 \mathrm{~h}$ and $168 \mathrm{~h}$ (7 days) and $100 \mathrm{mg}$ were exposed to 1,200 million lux hour ${ }^{-1}$ of UV radiation in a Tecnal TE-383 photoreactor, at $25^{\circ} \mathrm{C}$ for $24 \mathrm{~h}$. Subsequently, $0.1 \mathrm{mg} \mathrm{mL}^{-1}$ AMB solutions were prepared by weighing approximately $25 \mathrm{mg}$ of the degraded AMB and transferred to $25 \mathrm{~mL}$ volumetric flasks, then $5 \mathrm{~mL}$ of DMSO were added, homogenized and the volume was filled with methanol HPLC grade. One milliliter of this solution was pipetted and transferred to a $10 \mathrm{~mL}$ volumetric flask, and the volume was filled with methanol HPLC grade. It was filtered through a $0.45 \mu \mathrm{m}$ PTFE membrane and injected into HPLC-DAD at $\lambda_{\max }$ of $383 \mathrm{~nm}$ and scanning wavelengths from 200 to $400 \mathrm{~nm}$. The assays were performed in triplicate.

\section{Amphotericin B control solutions}

Amphotericin B $0.1 \mathrm{mg} \mathrm{mL}^{-1}$ solution were placed in a Binder VD 115 oven at $60 \pm 5^{\circ} \mathrm{C}$ for a period of $30 \mathrm{~min}$ (Control $30 \mathrm{~min}$ ), $60 \mathrm{~min}$ (Control $60 \mathrm{~min}$ ) and $240 \mathrm{~min}$ (Control $240 \mathrm{~min}$ ). Each solution was applied in the chromatographic system, in triplicate.

\section{Blank solutions}

For each stress solution, a blank solution was prepared under the same conditions without AMB. Blank, acid blank, alkaline blank, oxidative blank and blank in the presence of water were produced.

Identification of the main AMB degradation products after stress reactions

In order to identify the degradation products in each stress condition, the solutions of degraded samples of $\mathrm{AMB}$ and $\mathrm{AMB}$ solution $\mathrm{t}_{0}\left(0.1 \mathrm{mg} \mathrm{\textrm {mL } ^ { - 1 }}\right.$ AMB solution $)$ were injected by direct-infusion in the mass spectrometer. The electrospray ionization in positive mode mass spectrometry (ESI(+)-MS) and electrospray ionization in positive mode tandem mass spectrometry (ESI(+)-MS/MS) spectra were obtained by using samples prepared with methanol HPLC grade and the degrading agent at ratios according to Table 2, which were injected using an automatic injection pump.

\section{Results and Discussion}

To optimize the chromatographic parameters of the HPLC-DAD method (mobile phase composition, mobile phase flow rate, column type, column temperature, injection volume, wavelength (detection), environmental parameters of the analyses) and obtain a good resolution and a suitable AMB peak shape, several chromatographic conditions were tested. After optimizing these parameters, the suitability of the system was verified, according to Table 1 . Then, the HPLC-DAD method was validated and the chromatographic profiles in each stress condition, proposed in the AMB forced degradation study, were verified. Finally, the main degradation products of AMB after stress using the ESI(+)-MS with direct-infusion, were suggested.

Selection of the chromatographic parameters for the indicative stability method of AMB by HPLC-DAD

The chromatographic parameters used in the study were based on those presented by Wang et al. ${ }^{18}$ with some changes in the mobile phase ratio, the length of the chromatographic column and the detection wavelength. The wavelength used for AMB detection and its related substances was $383 \mathrm{~nm}$. This is due to the fact that AMB and its impurities have maximum absorption peaks at 383 and $407 \mathrm{~nm}$, and therefore, the use of these wavelengths for detecting such substances would not affect the detection sensitivity. ${ }^{19}$

The composition of the mobile phase considered to be the most suitable for the chromatographic performance of the AMB forced degradation study was a mixture at 65:35 ratio of organic phase (41:18-methanol:acetonitrile): $2.5 \mathrm{mmol} \mathrm{L}^{-1}$ disodium edetate, $\mathrm{pH}$ 5.0. The use of disodium edetate is justified by the probable presence of metals on the silica surface of the chromatographic column (C18 column). ${ }^{19}$ The presence of metals on the silica surface increases the acidity of the silanol groups and the broadening of the chromatographic peaks of basic compounds, and even irreversible retention of these compounds may occur, which negatively affects column performance. ${ }^{20}$ The optimization of the chromatographic analyzes for AMB detection with the use of disodium edetate in the mobile phase was also verified in other studies. ${ }^{21-23}$

After optimizing the chromatographic parameters, the system was adjusted. The parameters found were within the limits established in Table 1 as: number of theoretical plates $=5034$; tail factor $=1.8$, capacity factor $\left(\mathrm{K}^{\prime}\right)=6.71$ and purity of the appropriate API peak, since the limit angle (LA) 0.148 remained greater than peak purity angle (PA) 0.265 , relative standard deviation (RSD) 1.3 .

\section{Validation of the indicative stability methodology for AMB}

Validation must demonstrate that the analytical method produces reliable results and is appropriate to its intended 
purpose in a well-documented manner and based on objective criteria. Considering that the proposed method is an assay for API dosing in order to verify whether it has degraded or not, the tests necessary for validation, in this case, are: selectivity, linearity, accuracy, precision (repeatability), intermediate precision, limits of detection (LOD) and quantification (LOQ). ${ }^{14}$

\section{Selectivity}

In order to evaluate the method selectivity, blank solution was injected into a HPLC-DAD system. The obtained chromatogram was compared with the AMB standard (Figure 2a) and the $0.1 \mathrm{mg} \mathrm{mL}^{-1} \mathrm{AMB}$ sample $\left(A M B t_{0}\right)$ (Figure $2 b$ ). The AMB $t_{0}$ sample showed an AMB peak in approximately $18 \mathrm{~min}$, as it can be also verified in the standard solution. Blank analysis discloses that there are no peaks at this retention time, indicating that the diluents does not interfere with the AMB quantification. Selectivity can be also demonstrated with the results of the forced degradation study, analyzing the purity of the AMB peak and its resolution with the nearest peak, data that will be verified later.

\section{Linearity and standard AMB calibration curve}

Linearity was evaluated using a calibration curve to check the ability of the analytical method to obtain a proportional response to the analyte concentration in the sample. Based on eight concentrations from 0.05 to $0.12 \mathrm{mg} \mathrm{mL}^{-1}$ of $\mathrm{AMB}$, in triplicate, the linearity of the analytical method was evaluated and a calibration curve was constructed. The regression equation of the line was obtained $\left(\mathrm{Y}=1.3 \times 10^{8} \mathrm{X}-882893\right)$, resulting in the correlation coefficient ( $r$ ) higher than 0.990 , indicating the quality of curve. The significance of regression and the lack of adjustment with $95 \%$ confidence $(p \leq 0.05)$ were also verified through analysis of variance (ANOVA), since the calculated $F$ value was higher than the list $F$ value and the lack of adjustment was not significant at the same level of confidence.

\section{Accuracy and precision}

The calculated percentage recovery range was 98.08 to $99.96 \%$, which is within the designated specification of $100 \pm 2 \%$ and evidences the accuracy of the method.

The RSD values in the precision (repeatability) and intermediate precision experiments were lower than $2.0 \%$. In the analysis of intermediate precision, the variance study was performed by a $F$-test, which gave a $F_{\text {calculated }}(0.86)$ lower than the $F_{\text {table }}(5.05)$ with $95 \%$ confidence, indicating the preciseness of the method.

\section{Limit of detection and limit of quantification}

LOD and LOQ were determined based on signalto-noise concept, using signal-to-noise ratio at 3:1 and 10:1, respectively. The results were found to be LOD $0.1 \mu \mathrm{g} \mathrm{mL} \mathrm{m}^{-1}$ and LOQ $1.0 \mu \mathrm{g} \mathrm{mL}^{-1}$.

\section{Evaluation of the AMB forced degradation study conditions}

The degradation conditions of the AMB were selected (Table 2), and the method proved to be selective for the analyte with good resolution between AMB and its
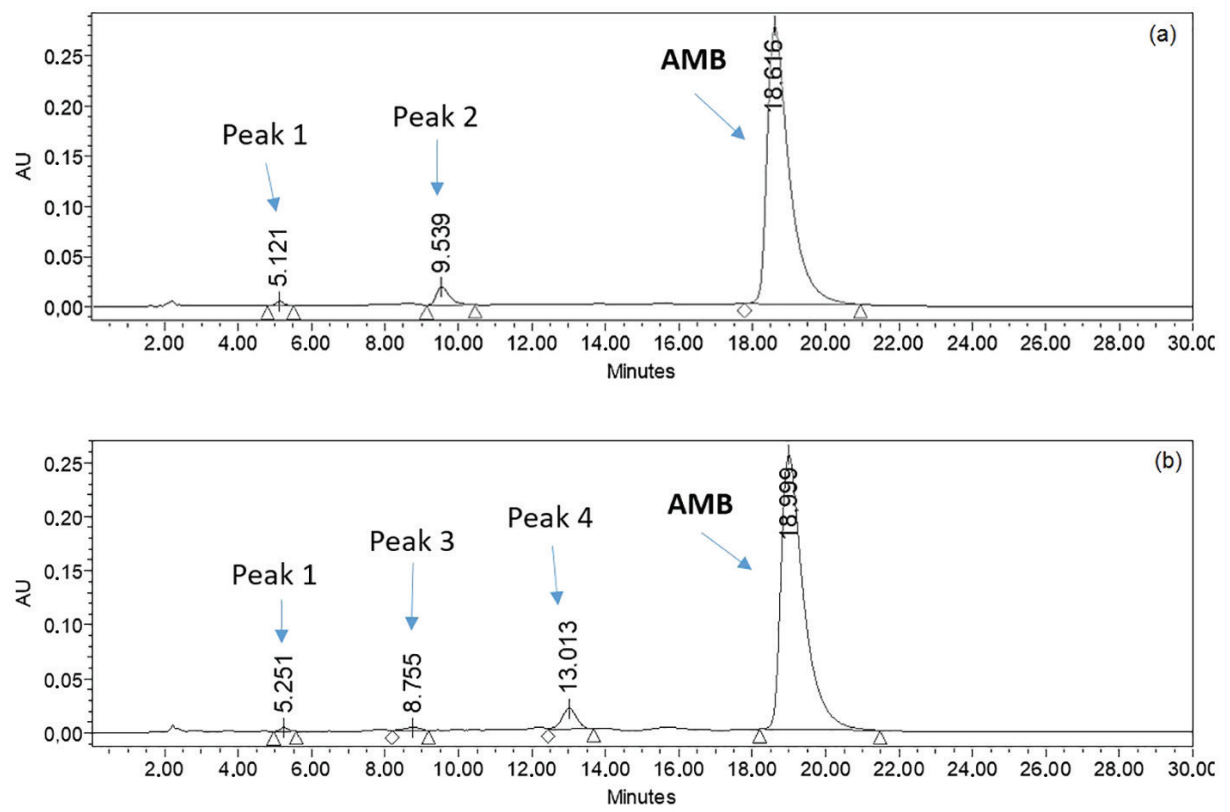

Figure 2. Representative HPLC chromatograms of (a) $0.1 \mathrm{mg} \mathrm{mL}^{-1} \mathrm{AMB}$ standard and (b) $0.1 \mathrm{mg} \mathrm{mL}^{-1} \mathrm{AMB}$ sample (AMB $\mathrm{t}_{0}$ ) at $383 \mathrm{~nm}$. 
impurities. Even under stress conditions, the drug peak remained spectrally pure. The impurities and AMB showed $\lambda_{\max }$ at 364 and $384 \mathrm{~nm}$, indicating that the structure of the long chain conjugated double bonds of impurities and AMB are practically identical. ${ }^{18}$

\section{AMB acid degradation}

The AMB degradation percentage in acid medium was $19 \pm 0.7 \%$ and its main degradation products are represented in Figure 3b by peak 6 (10 min) and peak 7 (12 min). In order to identify the main components of the sample after acid degradation, mass spectra were obtained by direct-infusion ESI(+)-MS of the AMB $\mathrm{t}_{0}$ samples (Figure 4a) and the AMB sample after acid hydrolysis (Figure 4b). In Figure 4, M corresponds to amphotericin B and M1 to amphotericin B (2).

The presence of the molecular ions $\mathrm{m} / \mathrm{z}, 946.50$ and $\mathrm{m} / \mathrm{z}$ 906.25 in AMB $\mathrm{t}_{0}$ (Figure 4a) is noted, which correspond to the sodium adduct of the AMB $\left([\mathrm{M}+\mathrm{Na}]^{+}\right),{ }^{23,24}$ and the loss of methoxy group in amphotericin B (2) (AMB (2)), $\left[\mathrm{M} 1+\mathrm{H}-\mathrm{CH}_{3} \mathrm{OH}\right]^{+} .{ }^{25}$ The presence of $m / z .906 .25$ ion indicates that the AMB (2) was already present in the AMB $\mathrm{t}_{0}$ sample.

In the mass spectrum of the AMB solution after acid hydrolysis, Figure $4 \mathrm{~b}$, the main peaks are: $\mathrm{m} / \mathrm{z}, 906.25$ $\left[\mathrm{M} 1+\mathrm{H}-\mathrm{CH}_{3} \mathrm{OH}\right]^{+}$ions (degradation product 1-DP1), $\mathrm{m} / \mathrm{z}$ $960.42[\mathrm{M} 1+\mathrm{Na}]^{+}$, related to the amphotericin B (2) sodium adduct $(\mathrm{AMB}(2))$ and $m / z 743.25\left[\mathrm{M} 1-\mathrm{CH}_{3} \mathrm{O}-\mathrm{C}_{6} \mathrm{H}_{13} \mathrm{NO}_{4}\right]^{+}$ ion, where the methoxy group and the glucosamine moiety of the AMB molecule are released, forming the degradation product 2-DP2 (Figure 5).

\section{AMB basic degradation}

In alkaline medium, the $\mathrm{pH}$ was 12 and the AMB degradation percentage was $14.4 \pm 0.4 \%$. The number of peaks remained the same as in the AMB $\mathrm{t}_{0}$, according to Figure 6; however, the area of the peaks around $5 \mathrm{~min}$ (peak 1) and $12 \mathrm{~min}$ (peak 4) increased. Compound related to peak 1 went from 0.007 to $0.01 \mathrm{mg} \mathrm{mL}^{-1}$, and compound related to peak 2 went from 0.009 to $0.012 \mathrm{mg} \mathrm{mL}^{-1}$, indicating that they are possibly degradation products of this API. The fast degradation of AMB in basic medium was also observed by Hamilton-Miller ${ }^{26}$ (utilizing biological activity data) when the degradation profile of AMB with $\mathrm{pH}$ variation was demonstrated. In this experiment, the half-life of AMB at pH 6, 7 and 8 was higher in $160 \mathrm{~h}$; at $\mathrm{pH} 4$ and 10, it was $140 \mathrm{~h}$ and at extreme $\mathrm{pH}$, like 2 and 12 , the half-life was less than $5 \mathrm{~h}$, which shows that this API rapidly degrades at very acidic and very alkaline $\mathrm{pH}$. Rajagopalan et al..$^{27}$ used HPLC-UV and found that $92 \%$ of AMB degraded at $\mathrm{pH} 12$ over a period of $3 \mathrm{~h}$. When complexed with cyclodextrin $1: 1$, the same degradation percentage was $3 \%$, over the same period. This fact occurs since the hydrophobic cavity of the cyclodextrin involves the hydrophobic part of the AMB molecule, blocking the main sites that can be linked with hydroxylic ions at $\mathrm{pH} 12$ and reducing its degradation under these conditions. No degradation product was identified in this study.

Like in acid degradation, mass spectra were obtained by direct-infusion ESI(+)-MS to check the main ions in the AMB samples after alkaline hydrolysis (Figure 7).

The most expressive ion is $m / z$ 968.50. Considering that the formation of sodium salt of the carboxylic acid in
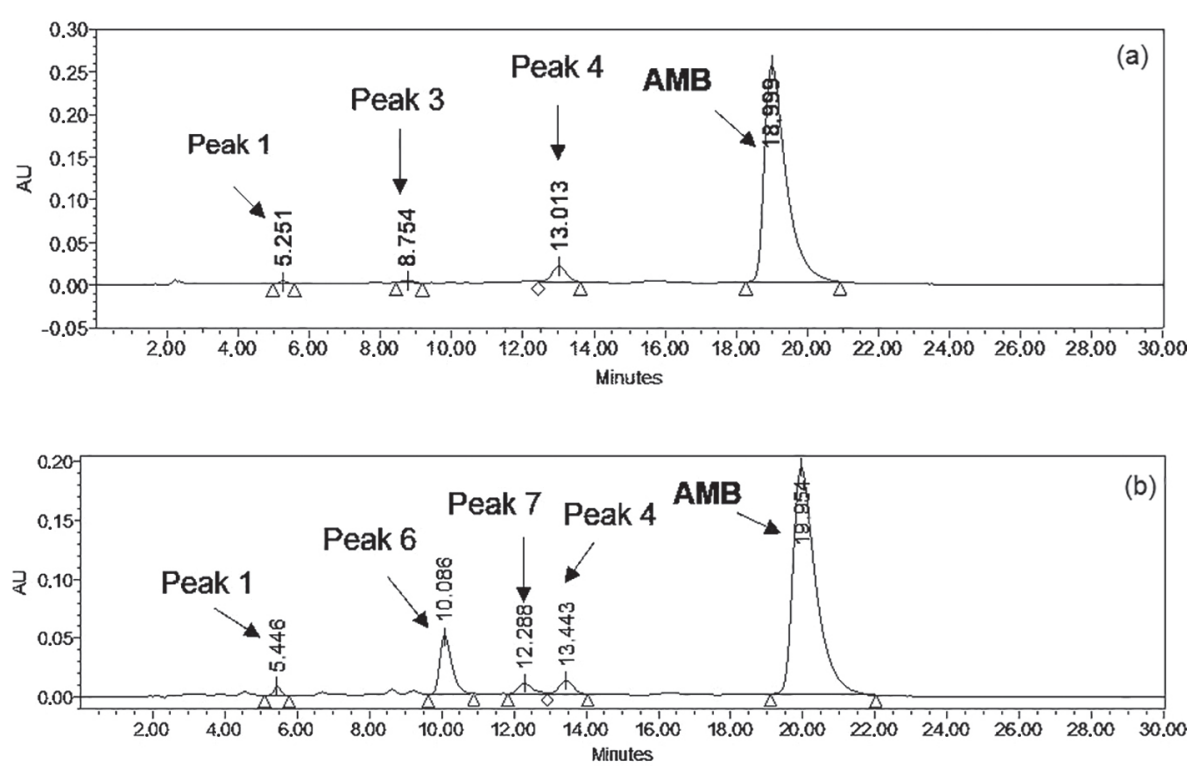

Figure 3. Representative HPLC chromatograms at $383 \mathrm{~nm}$ of AMB at (a) $\mathrm{t}_{0}$ and (b) after acid degradation (after exposed to $\mathrm{HCl} 0.01 \mathrm{~mol} \mathrm{~L}^{-1}$ ). 
TO(2) POSITNO FULL\#1 RT: 0,00 AV: 1 NL: 6,48E4

T: ITMS + p ESI Full ms $[235,00-1000,00]$

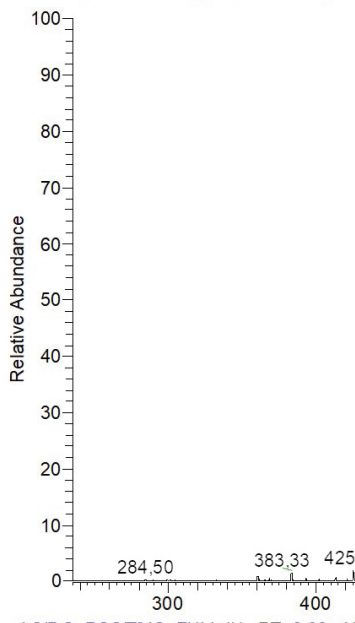

(b) ACIDO_POSITNO_FULL\#1 RT: 0,00 AV: 1 NL: 1,49E4 TMS + p ESI Full ms [185,00-1000,00]

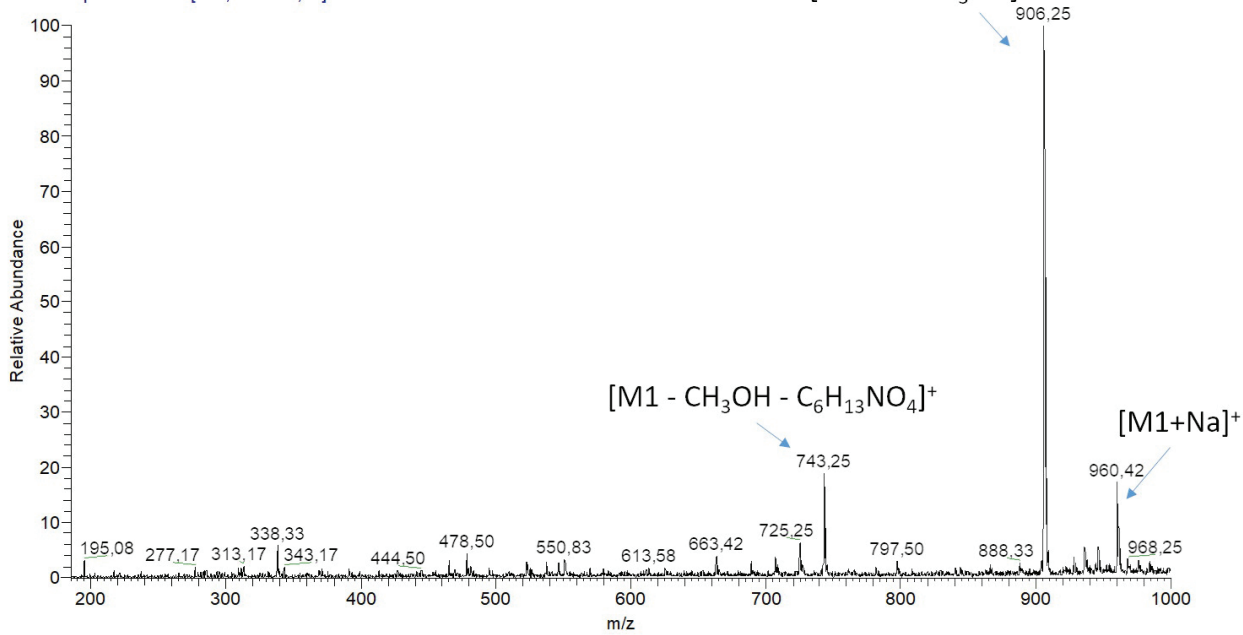

Figure 4. Positive ion mass spectra (ESI(+)-MS) of the $\mathrm{m} / \mathrm{z}$ range $200-1000$ of (a) $\mathrm{AMB}_{0}$ and(b) $\mathrm{AMB}$ after acid hydrolysis (after exposed to $\mathrm{HCl} 0.01 \mathrm{~mol} \mathrm{~L}^{-1}$ ) (M corresponds to AMB and M1 to AMB (2)).
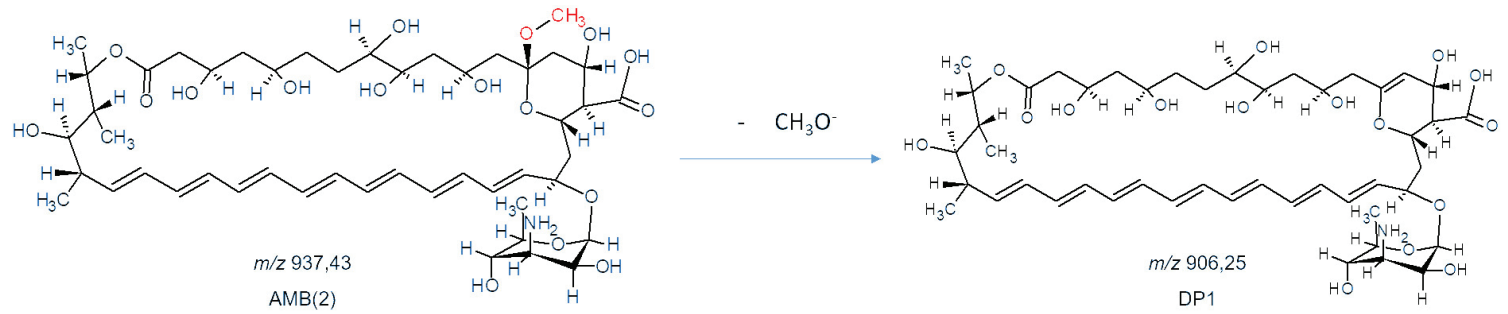

$-\mathrm{C}_{6} \mathrm{H}_{13} \mathrm{NO}_{4}$

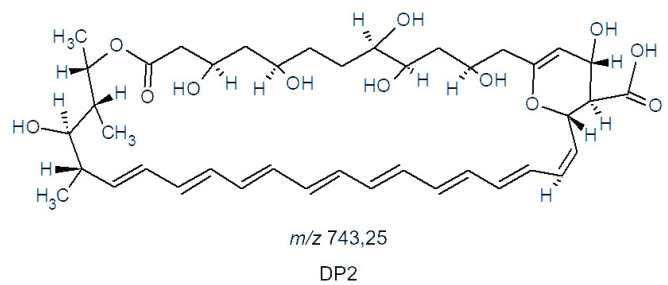

Figure 5. Amphotericin B (2) fragmentation proposal in acid media for formation of molecules with $\mathrm{m} / z$.906.25 (DP1) and $\mathrm{m} / \mathrm{z}$, 743.25 (DP2). 

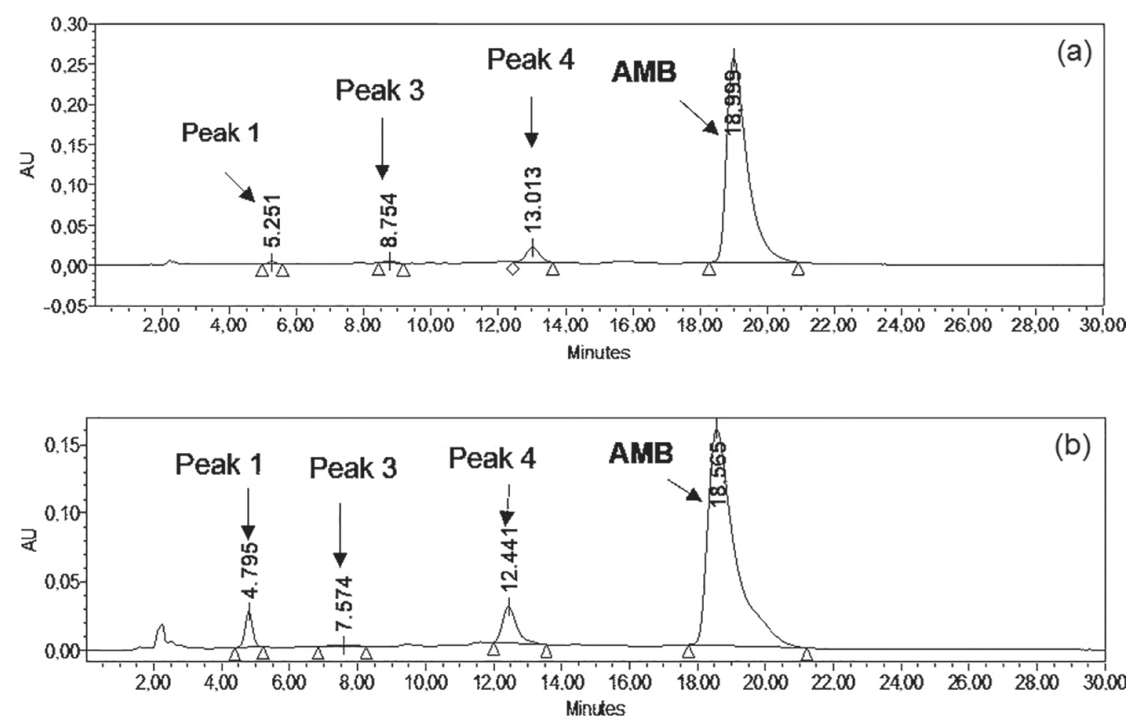

Figure 6. Representative HPLC chromatograms at $383 \mathrm{~nm}$ of AMB at (a) $\mathrm{t}_{0}$ and (b) after alkaline degradation (after exposed to $\mathrm{NaOH} 0.001 \mathrm{~mol} \mathrm{L^{-1 }}$ ).

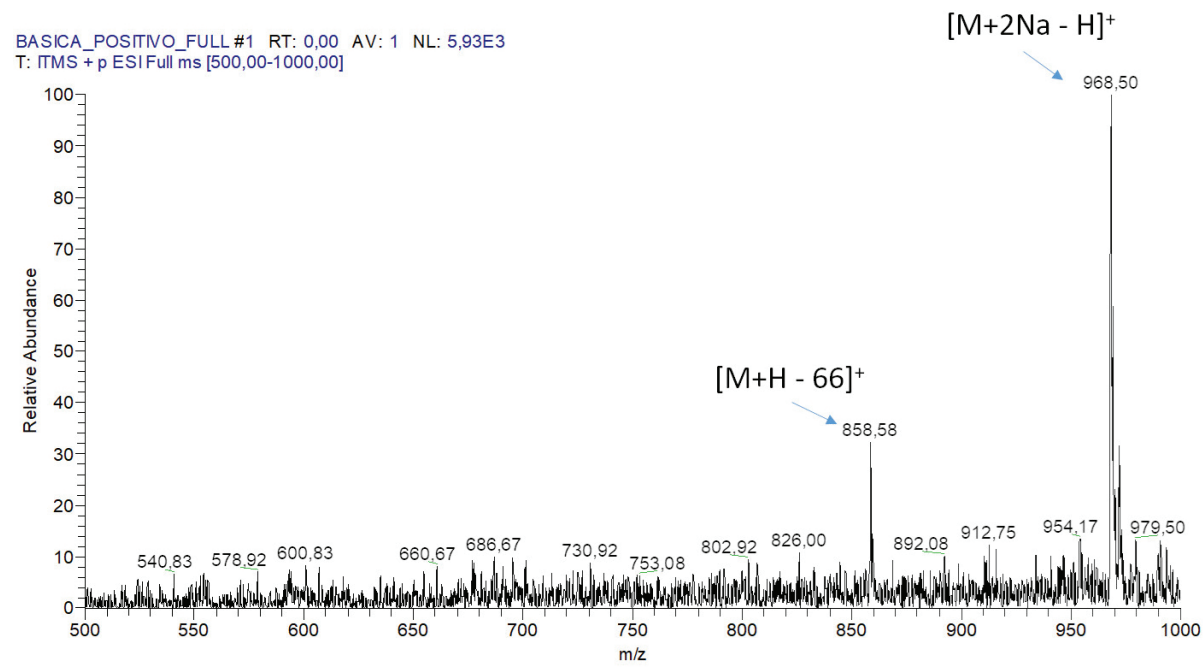

Figure 7. Positive ion mass spectra (ESI(+)-MS) of the $m / z$ range 500-1.000 of AMB after alkaline hydrolysis (M corresponds to AMB).

AMB and its sodium adduct, to give a sodiated sodium salt of AMB, it can be suggested that $\mathrm{m} / \mathrm{z} 968.50$ is related to $\mathrm{AMB}[\mathrm{M}+2 \mathrm{Na}-\mathrm{H}]^{+}$.

\section{AMB oxidative degradation}

Considering that the conjugated double bonds present in the AMB structure are targets for oxidation-induced degradation, ${ }^{28}$ the oxidation of this API was verified by injecting samples immediately after addition of $3 \% \mathrm{H}_{2} \mathrm{O}_{2}$ $\left(\mathrm{t}_{1}\right)$, after $30 \mathrm{~min}\left(\mathrm{t}_{2}\right)$ and after $60 \mathrm{~min}\left(\mathrm{t}_{3}\right)$ in an oven at $60 \pm 2{ }^{\circ} \mathrm{C}$. In $\mathrm{t}_{3}$, the percentage of AMB degradation was $21.4 \pm 0.6 \%$, while in the other conditions, it was less than $10 \%$. Therefore, we decided to carry out the study in $\mathrm{t}_{3}$. A blank study with $\mathrm{AMB}$ at $60 \mathrm{~min}, 60^{\circ} \mathrm{C}$ without $\mathrm{H}_{2} \mathrm{O}_{2}$ was performed. A peak at 9.5 min was observed and the concentration of AMB decreased in this condition. Studies have shown that AMB, in the presence of DMSO and methanol at $60{ }^{\circ} \mathrm{C}$ for $60 \mathrm{~min}$, produced AMB (2) as degradation product. ${ }^{25,29}$

Analyzing the chromatographic profile of the oxidized AMB, Figure 8 shows the appearance of peaks 2, 12 and 13. The degraded samples were injected in ESI(+)-MS (Figure 9), showing that the major ions formed were $m / z, 960.42$ indicating the presence of the sodium adduct AMB (2) $[\mathrm{M} 1+\mathrm{Na}]^{+} ; m / z 906.25$ of DP1 and $m / z 743.25$ of DP2.

Other AMB degradation studies have shown that, in the presence of oxygen, this API degrades rapidly. In 2014, Kumar et al. ${ }^{12}$ found that AMB has significant sensitivity in the presence of a $30 \% \mathrm{H}_{2} \mathrm{O}_{2}$ solution. Dicken et al..$^{21}$ studied the chemical stability of AMB in $N, N$-dimethylacetamide 


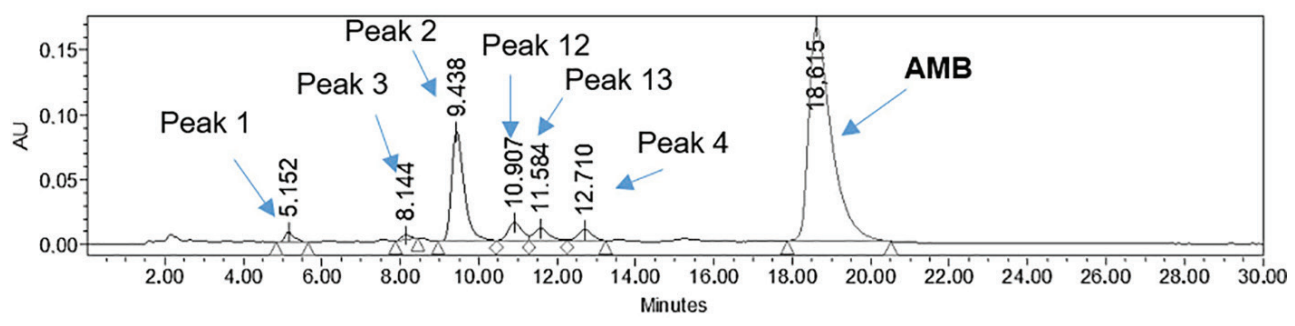

Figure 8. Representative HPLC chromatograms at $383 \mathrm{~nm}$ of AMB after oxidation ( $\mathrm{t}_{3}$-after exposed to $3 \% \mathrm{H}_{2} \mathrm{O}_{2}, 60 \pm 2{ }^{\circ} \mathrm{C}$ for $60 \mathrm{~min}$ ).

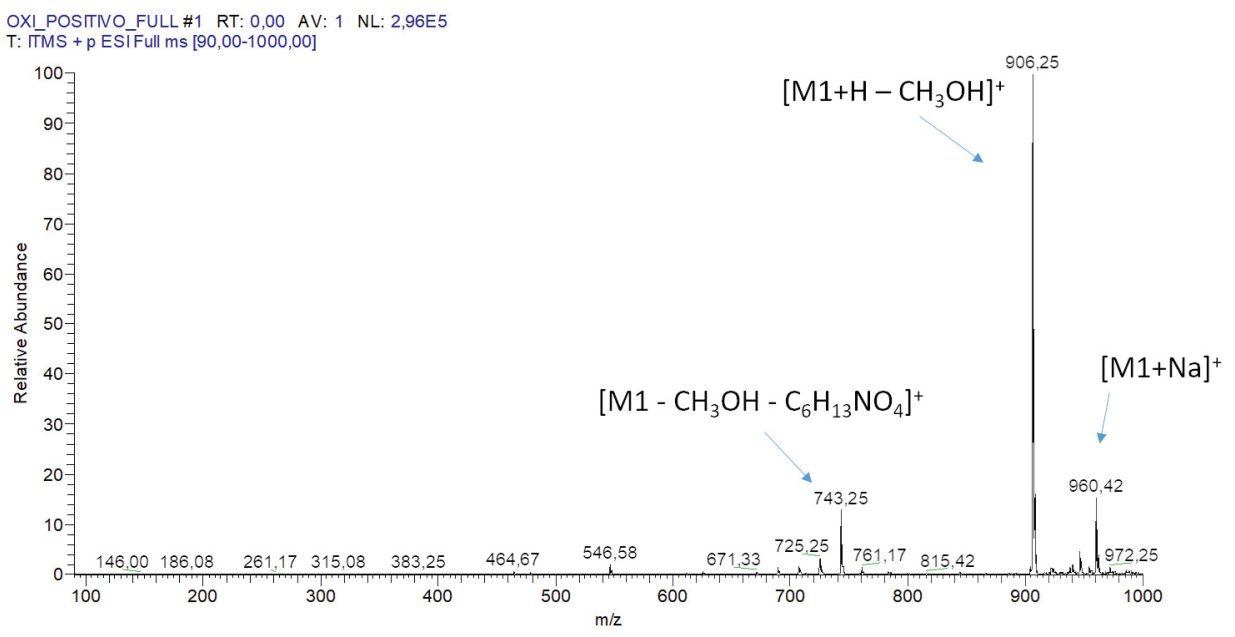

Figure 9. Positive ion mass spectra (ESI(+)-MS) of the $m / z$ range $100-1000$ of AMB after oxidation ( $\mathrm{t}_{3}$-after exposed to $3 \% \mathrm{H}_{2} \mathrm{O}_{2}, 60 \pm 2{ }^{\circ} \mathrm{C}$ for 60 min) (M1 corresponds to AMB (2)).

and verified the stability of a $1 \%$ AMB solution in sodium deoxycholate and $N, N$-dimethylacetamide in the presence and absence of oxygen. They concluded that, in the presence of oxygen, the decomposition of AMB occurs 3 to 5 times faster than in anaerobic medium. In these studies, no degradation product of AMB was identified.

\section{AMB hydrolysis}

The experiments demonstrated that there was no significant AMB degradation in the presence of water. This was also verified by Dicken et al. ${ }^{21}$ and Kumar et al. ${ }^{12}$ in AMB degradation studies. The low AMB degradation in the presence of water may be related to its low solubility in aqueous medium and neutral $\mathrm{pH} .{ }^{30}$ That is why, under aqueous conditions, this API is normally arranged as large micelles consisting of many molecules and, due to the hydrophobic and hydrophilic forces of AMB, it can confer protection, since the sensitive regions of the molecule may be partially protected. ${ }^{31}$

\section{AMB thermal degradation}

In the thermal degradation experiment, $\mathrm{AMB}$ was exposed to $70 \pm 2{ }^{\circ} \mathrm{C}$ for $24 \mathrm{~h}\left(\mathrm{t}_{1}\right)$ and $168 \mathrm{~h}$ ( 7 days) $\left(\mathrm{t}_{2}\right)$.
By HPLC-DAD, there was no evidence of reduction of the AMB peak area or for the formation of peaks due to degradation. The AMB stability at high temperatures was also observed by Kumar et al. ${ }^{12}$ No significant degradation was verified at $60^{\circ} \mathrm{C}$, for 7 days.

\section{AMB photolysis}

Two peaks were observed, in HPLC-UV, under this degradative condition (Figure 10a): peak 15 (7.7 $\mathrm{min})$ and peak 16 (15.5 min) when compared with the chromatographic profile of $\mathrm{t}_{0}$ (Figure 10b). The percentage of AMB degradation was $10.6 \pm 0.4 \%$. Such degradation can be explained based on the presence of the macrolactone ring and a long unsaturated chain, which confers to AMB a wide possibility of physical and chemical attacks. ${ }^{28}$ According to Hung et al. ${ }^{9}$ this drug is more stable in dark environments than in the presence of light.

In order to confirm the degradation of AMB in the presence of light, the sample after photolysis was injected in ESI(+)-MS, obtaining the spectrum shown in Figure 11, where the ions $m / z 858.50$ and $m / z 968.50$, which are not present in the spectrum of the AMB $\mathrm{t}_{0}$, were seen. 

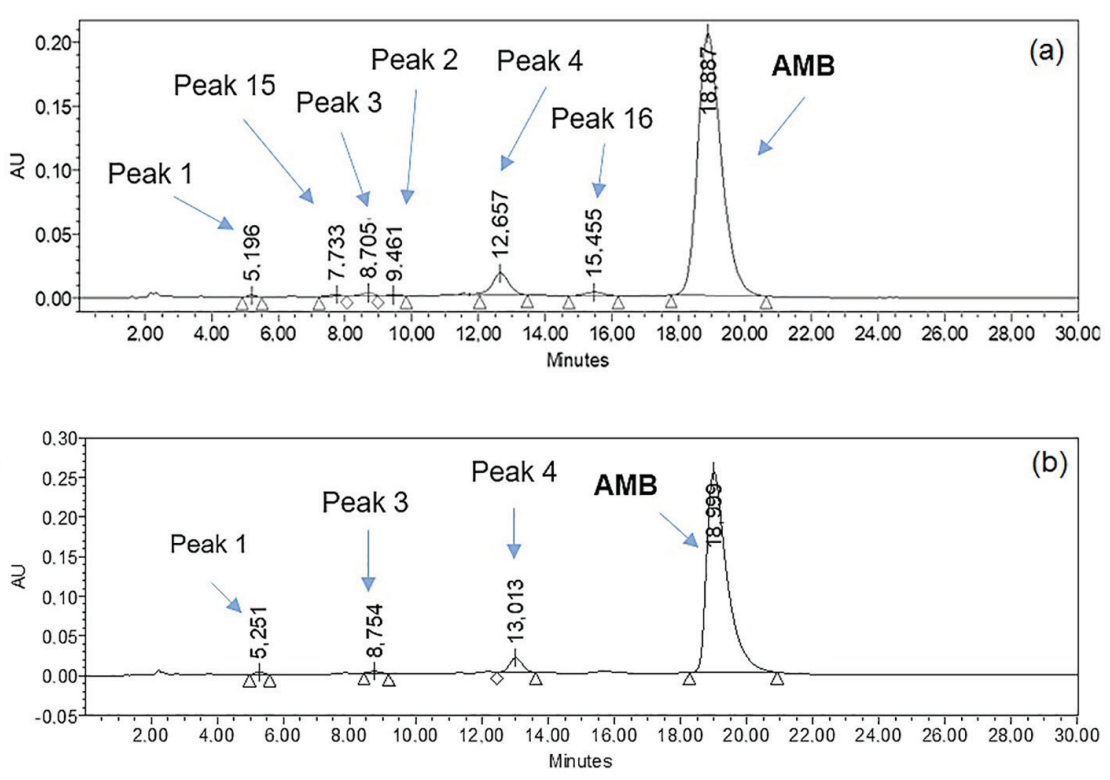

Figure 10. Representative HPLC chromatograms at $383 \mathrm{~nm}$ of AMB (a) after photolysis (after $24 \mathrm{~h}$ exposed to 1,2 million lux hour ${ }^{-1}$ ) and in (b) $\mathrm{t}_{0}$.

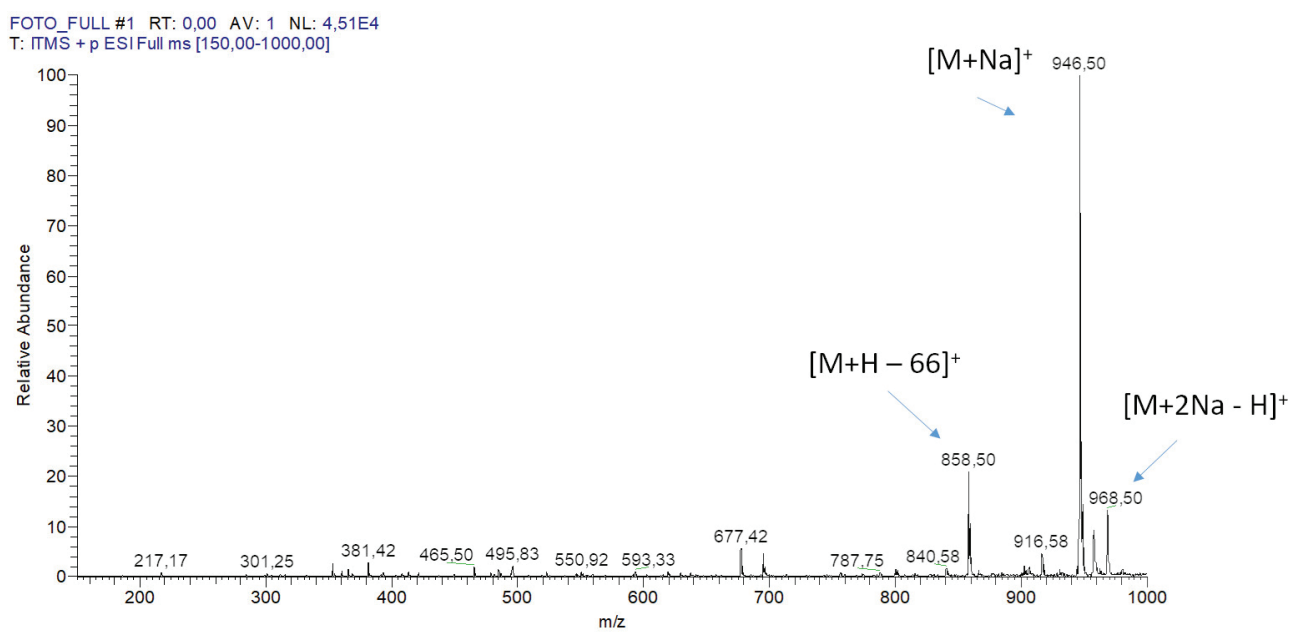

Figure 11. AMB mass spectrum after photolysis (after $24 \mathrm{~h}$ exposed to 1,2 million lux hour ${ }^{-1}$ ) in ESI(+)-MS 200-1000 m/z.

\section{Conclusions}

The AMB degradation study was adjusted not to cause a large deterioration of the drug involved, but in a safe stress, between 10 and $30 \%$, thus avoiding secondary degradations. Considering the chromatographic profiles of the AMB degradations presented, it is suggested that the method used is stable, selective and with good resolution between AMB and the other impurities generated under stress. The methodology was validated and proved to be efficient for its intended purpose, maintaining a strict control of the chromatographic parameters. It was found that the AMB is stable in the presence of water and at $70 \pm 2{ }^{\circ} \mathrm{C}$ for 7 days and susceptible to degradation at extreme $\mathrm{pH}$ in the presence of oxygen and light.

By means of direct-infusion ESI(+)-MS of the degraded solutions, it can be suggested that AMB (2), DP1 and DP2 were produced in acid and oxidative medium. The mechanisms proposed to explain the formation of these degradation products (Figure 5) have not yet been fully clarified and require additional experimental and theoretical studies to formulate a consistent proposal.

\section{Acknowledgments}

Authors thank CNPq, CAPES and FAPERJ for financial support.

\section{References}

1. International Conferences on Harmonization (ICH); Guideline (ICH-Q1A (R2)): Stability Testing of New Drug Substances and 
Products, 2003, available at https://www.fda.gov/media/71707/ download accessed in October 2019.

2. Hasija, M.; Rahman, N.; Ausar, S. F.; Vaccine 2013, 3, 11.

3. Brummer, H.; Life Sci. 2011, 31, available at https://www. sgsgroup.at/ /media/Global/Documents/Technical\%20 Documents/SGS-LSS-Forced\%20Degradation-EN-11.pdf accessed in October 2019.

4. Swarbrick, J.; Baertschi, S. W.; Jansen, P. J.; Alsante, K. M.; Reed, R. A.; Pharmaceutical Stress Testing, vol. 13, $1^{\text {st }}$ ed.; Taylor \& Francis Group, Eli Lilly and Company Indianapolis: Indianapolis, USA, 2005.

5. Alsante, K. M.; Ando, A.; Brown, R.; Ensing, J.; Hatajik, T. D.; Kong, W.; Tsuda, Y.; Adv. Drug Delivery Rev. 2007, 59, 29.

6. International Conferences on Harmonization (ICH); Guideline (ICH Q3A (R2)): Impurities in New Drug Substances (Review 2), 2006, available at https://www.fda.gov/media/71733/ download accessed in October 2019.

7. European Medicines Agency (EMA); Guideline on Setting Specifications for Related Impurities in Antibiotics, 2012, available at https://www.ema.europa.eu/documents/scientificguideline/adopted-guideline-setting-specifications-relatedimpurities-antibiotics_en.pdf accessed in October 2019.

8. Trejo, W. H.; Bennett, R. E.; J. Bacteriol. 1963, 85, 436.

9. Hung, C. T.; Lam, F. C.; Perrier, D. G.; Souter, A.; Int. J. Pharm. 1988, 44, 117.

10. Sundar, S.; Chakravarty, J.; Agarwal, D.; Rai, M.; Murray, H. W.; N. Engl. J. Med. 2010, 362, 504.

11. Rodrigo, C.; Weeratunga, P.; Fernando, S. D.; Rajapakse, S.; Clin. Microbiol. Infect. 2018, 24, 591.

12. Kumar, D.; Trivedi, N.; Shivastava, S.; Dixit, R. K.; Int. J. Pharm Sci. 2014, 6, 289.

13. World Health Organization (WHO); Accelerated Stability Studies of Widely Used Pharmaceutical Substances under Simulated Tropical Conditions, 1986, available at http://apps. who.int/medicinedocs/pdf/h1808e/h1808e.pdf accessed in October 2019.

14. International Conferences on Harmonization (ICH), Guideline (ICH Q2(R1)); Validation of Analytical Procedures: Text and Methodology (R4), 2005, available at https://www.ema.europa. eu/en/documents/scientific-guideline/ich-q-2-r1-validationanalytical-procedures-text-methodology-step-5_en.pdf accessed in October 2019.

15. Origin Pro 7; OriginLab, Northampton, USA, 2007.

16. The United States Pharmacopeia, USP 39-NF 29, United States Pharmacopeial Convention: Rockville, 2016.

17. Empower 3 Data Acquisition and Processing Theory Guide, version 2010/1, Review A; Waters Corporation, Milford, USA, 2010.

18. Wang, Y. H.; Zhang, I. P.; Chang, Y.; Hu, C. Q.; J. Antibiot. 2010, 63, 553.

19. Chang, Y.; Yong-Hong, W.; Chang-Qin, H.; J. Antibiot. 2011, 64,735 .

20. da Silva, C. G. A.; Collins, C. H.; J. Chromatogr. A 2012, 1260 , 81.

21. Dicken, C. M.; Rossi, T. M.; Rajagopalan, N.; Int. J. Pharm. 1988, 46, 223.

22. Manosroi, A.; Kongkaneramit, L.; Manosroi, J.; Int J. Pharm. 2004, 270, 279.

23. Aszalos, A.; Bax, A.; Burlinson, N.; Roller, P.; Mcneal, C.; J. Antibiot. 1985, 38, 1699.

24. Kruve, A.; Kaupmees, K.; Liigand, J.; Oss, M.; Leito, I.; J. Mass Spectrom. 2013, 48, 695.

25. Li, J.; Zhu, H. Q.; Li, J.; Jin, S. H.; Hu, C. Q.; J. Antibiot. 2007, 60, 272.

26. Hamilton-Miller, J. M. T.; J. Pharm. Pharmacol. 1973, 25, 401.

27. Rajagopalan, N.; Chen, S. C.; Chow, W. S.; Int. J. Pharm. 1986, 29, 161.

28. Tufteland, M. L.; Selitrennikoffb, C. P.; Ryana, R. O.; Pest Manage. Sci. 2009, 65, 624.

29. Zhu, H.; Hu, C.; Zhao, X.; Chin. J. Pharm. Anal. 2006, $26,949$.

30. Connors, K. A.; Amidon, G. L.; Stella, V. J.; Chemical Stability of Pharmaceuticals: A Handbook for Pharmacists, $2^{\text {nd }}$ ed.; Wiley: New Jersey, USA, 1986.

31. Bonner, D. P.; Mechlinski, W.; Schaffne, C. P.; J. Antibiot. 1975, $28,132$.

Submitted: March 28, 2019

Published online: November 7, 2019 